\title{
El CONTRATO DE PRÉStamo DE VAlores
}

\author{
[“Securities Lending Contract"]
}

\author{
Alejandro Guzmán Brito* \\ Pontificia Universidad Católica de Valparaíso, Chile
}

\begin{abstract}
RESUMEN
La Ley $N^{\circ} 20.345$, de 2009, tipificó un contrato de préstamo de valores, consistente en dar un prestamista cierta cantidad de aquéllos a un prestatario, para que en un tiempo posterior éste le restituya otra tanta cantidad de valores del mismo emisor, género, cantidad, clase y serie, con la obligación de pagar, además, un premio en dinero. El artículo estudia los diversos temas y problemas dogmáticos que ofrece esta nueva figura típica, con excepción de los concernientes a las garantías establecidas por la ley para
\end{abstract}

\begin{abstract}
Law No. 20.345 of 2009 categorized security lending agreements, which is when a moneylender gives certain amount of securities to a borrower so that $s /$ he gives back another such amount of the same issuer, type, amount, class, and series with the obligation to also pay in prize money. This article studies the different dogmatic issues and problems resulting from this typical form, except those regarding the guarantees established by law for its enforcement, which were reserved for another work
\end{abstract}

* Doctor en Derecho por la Universidad de Navarra, España; profesor titular de Derecho romano de la Facultad de Derecho de la Pontificia Universidad Católica de Valparaíso. Dirección postal: Facultad de Derecho, Pontificia Universidad Católica de Valparaíso, Avenida Brasil 2950, Valparaíso, Chile. Correo electrónico: aguzman@ ucv.cl Agradezco las importantes observaciones que el colega José Luis Guerrero quiso hacer a este trabajo. 
su cumplimiento, que quedan reservados para otro trabajo.

Palabras clave

Valores - Préstamo de valores - Mutuo y préstamo de valores.
KEYWORDS

Securities - Securities Lending - Mutual funds and securities lending.

RECibido el 2 y aCEPTADo el 28 de mayo de 2012.

El título $6^{\circ}$ de la Ley $\mathrm{N}^{\circ} 20.345$ (DO. de 6 de junio de 2009) se rubrica: Del préstamo de valores y contiene en los artículos 38 a 40 que lo integran la regulación de un contrato denominado como indica la rúbrica. El presente trabajo queda destinado a estudiar los puntos más relevantes de la figura, con excepción del régimen de las cauciones celebradas para asegurar el cumplimiento de un contrato, que reservaremos para un artículo ulterior, atendida la minuciosidad de detalles que lo integran, cuyo tratamiento aquí dilataría demasiado este trabajo.

\section{CONCEPTO Y CARACTERES DEL PRÉSTAMO DE VALORES}

\section{Concepto.}

El artículo 39 de la Ley $\mathrm{N}^{\circ} 20.345$, de 2009, define que el préstamo de valores "es un contrato en virtud del cual una persona, llamada prestamista, transfiere valores a otra, llamada prestatario, quien asume la obligación de restituir al primero, al vencimiento del plazo pactado, valores del mismo emisor, género, cantidad, clase y serie y de pagar una suma de dinero, denominada premio". De acuerdo con esta definición, el préstamo de valores esencialmente consiste en una transferencia entre vivos de valores por una persona a otra, para que ésta devuelva al primero otros tantos valores del mismo emisor, género, cantidad, clase y serie. Aparentemente, también pertenece a la esencia de este contrato la obligación de pagar una suma de dinero, llamada premio, por el prestatario al prestamista. El transferente se llama "prestamista" y el accipiente, "prestatario".

El artículo 39 de la ley recurre a la noción de contrato para fijar en éste al género próximo del préstamo ("es un contrato en virtud del cual"). Y con razón, porque del acto en que consiste emanan obligaciones (artículo 1437 CC.), como lo veremos.

De la definición legal de este acto derivan sus caracteres más notables:

2. El préstamo de valores es un contrato obligacionalmente unilateral.

El préstamo de valores es un contrato obligacionalmente unilateral, pues 
tan sólo el prestatario contrae obligaciones; nunca el prestamista (cfr. artículo 1439 CC.). La obligación que ineludiblemente contrae el prestatario es la de restituir otro tanto de valores del mismo emisor, género, cantidad, clase y serie de los recibidos al prestamista: de faltar esta obligación el contrato degenera en donación. A aquélla puede añadirse en concepto de elemento natural la obligación de pagar el prestatario una suma de dinero, denominada "premio", al prestamista. A ella nos referiremos por separado más adelante, en el número 4 de este capítulo.

En tercer lugar, el prestatario queda eventualmente obligado a reembolsar los emolumentos percibidos por él a partir de los valores recibidos de que se hizo dueño merced a la transferencia en que consiste el contrato. A esta obligación eventual también nos referiremos por separado, en el capítulo VII.

\section{El préstamo de valores es un contrato real.}

a) El rasgo de ser real este contrato deriva de que el artículo 39 define que el prestamista "transfiere valores" al prestatario. Tal transferencia consiste en una tradición (cfr. artículo 1443 CC.), que en materia de valores se llama "cesión"; y asume diferentes formas según la estructura del valor: entrega de valores al portador, endoso de valores a la orden, cesión de valores nominativos ${ }^{1}$.

Cuando, en especial, se trata de acciones -que solo pueden ser nominativas- deben transferirse como ordena el artículo 15 del Reglamento de la Ley $\mathrm{N}^{\circ}$ 18.046: sobre Sociedades anónimas, el artículo 12 de la cual ley se remite a aquél ${ }^{2}$; y que, en síntesis, tiene lugar mediante una cesión (denominada traspaso en la jerga bursátil) consistente en una convención (contrato la llama el artículo 17 del Reglamento) celebrada entre el cedente y el cesionario por escritura pública, o bien, por escritura privada suscrita ante dos testigos mayores de edad, o un corredor de bolsa o un notario en orden a ceder ciertas acciones que se individualizan. La inscripción de la cesión en el Registro de Accionistas de la sociedad anónima de que se trate no es una solemnidad de la cesión ni constituye la manera de hacer la tradición de las acciones (que ya es perfecta por la cesión misma), sino una formalidad destinada a hacer oponible la cesión ante la sociedad emisora y terceros (artículo $17 \mathrm{del}$ Reglamento).

${ }^{1}$ Véanse el título $4^{\circ}$ del libro II CCom., el $\$ 2$ del título $1^{\circ}$ de la Ley $N^{\circ} 18.092$, que Dicta nuevas normas sobre letra de cambio y pagare (DO. de 14 de enero de 1982) y la Ley No 18.552, que Regula tratamiento de títulos de crédito (DO. de 20 de septiembre de 1986).

${ }^{2}$ Dicho reglamento está contenido en el Decreto supremo $N^{\circ} 587$, del Ministerio de Hacienda (DO. de 4 de agosto de 1982). 
El prestamista, pues, pierde el dominio de los valores que transfiere y, correlativamente, el prestatario adquiere el dominio de los recibidos.

b) Puede acaecer que los valores que se trata de prestar hayan sido previamente dejados en custodia de una sociedad de depósito de valores, de aquéllas regidas por la Ley $\mathrm{N}^{\circ} 18.876$ que Establece el marco legal para la constitución y operación de entidades privadas de depósito y custodia de valores (DO. de 5 de diciembre de 1989) ${ }^{3}$. El depósito del valor, a su vez, pudo haber sido de su título cartáceo o desmaterializado, de guisa que el valor tan solo conste en una cuenta a nombre del depositante y no exista título del mismo. Nada de esto, por cierto, impide que los valores depositados sean objetos de préstamo, aunque, en el caso, la transferencia deba hacerse de acuerdo con las reglas que presiden ese movimiento cuando se lo ejecuta sobre valores desmaterializados.

Se refieren a la materia los artículos $7^{\circ}$ y $8^{\circ}$ de la Ley $\mathrm{N}^{\circ} 18.876$.

El artículo 7 dispone: "Entre depositantes de una misma empresa, las transferencias de valores depositados que sean consecuencia de las operaciones que se realicen entre ellos, se efectuarán, mediante cargo en la cuenta de quien transfiere y abono en la del que adquiere, en base a una comunicación escrita $o$ por medios electrónicos que los interesados entreguen a la empresa. Esta comunicación, ante la empresa, será título suficiente para efectuar tal transferencia". Así que cuando el prestamista y el prestatario sean cliente de una misma empresa de depósito de valores, la transferencia de los prestados por el primero al segundo debe ejecutarse como se indica en este artículo.

El artículo 8, por su lado, prescribe: "Las transferencias en favor de terceros que no sean depositantes en la empresa se efectuarán mediante las formalidades propias de la transferencia del dominio, según sea la naturaleza del titulo de que se trate, con cargo a los valores disponibles que el depositante tenga en cuenta. El depositante comunicará a la empresa por escrito o por vía electrónica el nombre del beneficiario. Esta comunicación ante la empresa, constituirá título suficiente para efectuar tal transferencia”. Si, en cambio, los títulos están depositados por el prestamista y han de ser transferidos en préstamo a una persona que no tiene cuenta de valores en ninguna empresa del genero, para todas las cuales es, por ende, un tercero, o que la tiene en otra empresa distinta a aquella en la cual están depositados los valores objeto del contrato, respecto de la cual

${ }^{3}$ Ley $\mathrm{N}^{\circ} 18.876$, artículo 1 inciso $2^{\circ}$ : "Pueden ser objeto del depósito a que se refiere esta ley, los valores de oferta pública inscritos en el Registro de Valores que lleva la Superintendencia de Valores y Seguros, en adelante, la Superintendencia, los emitidos por los bancos o por el Banco Central de Chile, los emitidos o garantizados por el Estado y, en general, cualquier otro valor que autorice la Superintendencia mediante norma de carácter general". Compárense estos valores con los susceptibles de ser prestados, según se dirá en el capítulo IV, 1 , porque la coincidencia no es plena. 
es, por lo tanto, un tercero, la transferencia adquiere modalidades diferentes a las del caso anterior y que aparecen descritas en la norma.

c) El artículo 38 de la Ley $N^{\circ} 20.345$ establece: "[Inciso $1^{\circ}$ ] Con el objeto de asegurar el correcto funcionamiento del sistema, Las Cámaras de Compensación o de Contrapartes Centrales y las empresas de depósito de valores reguladas por la ley $N^{\circ} 18.876$,podrán establecer un registro de préstamo de valores en el cual se anotarán [...] las operaciones de préstamo de valores celebradas./ [Inciso $2^{\circ}$ ] Las sociedades administradoras podrán encargar a las empresas de depósito de valores regidas por la ley $N^{\circ} 18.876$, el registro establecido en el inciso anterior". Como se aprecia, el establecimiento de un "registro de préstamos de valores" es facultativo ("podrán establecer"). Pero si se establece, entonces es imperativo que las operaciones de préstamo de valores ya celebradas sean anotadas en él ("en el cual se anotarán"). Ahora bien, esta anotación no ha sido exigida como solemnidad del contrato de préstamo de valores, que lo perfeccione y sin la cual sería nulo, ni como formalidad para hacerlo oponible a terceros. Nada de eso está dicho en la ley. La cual solo la considera como un medio para asegurar el correcto funcionamiento del sistema de compensación y liquidación de instrumentos financieros, en cuanto imprime publicidad, no en función de oponibilidad, como quedó dicho, sino como información general a los participantes del sistema interesados en saber que actores de él cuentan con valores prestados que dan cobertura y solvencia a sus operaciones.

Conviene señalar que la omisión de anotar un préstamo en el registro no tiene sanción especial, y que su punición corre a cargo de la Superintendencia de Valores y Seguros, de acuerdo con las reglas generales 4 .

\section{El préstamo de valores puede ser un contrato oneroso o gratuito.}

Como quedó dicho al comenzar, la ley define que en este contrato el prestatario contrae la obligación de pagar una suma de dinero, denominada premio, al prestamista (artículo 39). Este premio, pues, aparenta constituir una contraprestación necesaria que hace el prestatario al prestamista por la dación de los créditos que le hace este último; o, si se quiere, el precio que el prestatario paga al prestamista por tal dación. Si la obligación de que hablamos fuera, en efecto, esencial en el contrato, éste tendría siempre el carácter de oneroso porque, en los términos del artículo 1440 CC., aquél resulta útil para ambos contratantes y cada cual se grava en beneficio del otro.

Se pregunta, con todo, si las partes pueden acordar expresamente que no haya premio en el contrato que celebran, caso en el cual, por aplicación de la misma disposición del Código Civil antes citada, aquél es gratuito, porque entonces solo tiene por objeto la utilidad del prestatario y el prestamista es

\footnotetext{
${ }^{4}$ Véase, por ejemplo, el artículo 41 de la Ley $\mathrm{N}^{\circ} 20.345$.
} 
el único que sufre gravamen. De esta manera, la cuestión puede ser planteada así: el premio, ¿es de la esencia del contrato o solo de su naturaleza (artículo 1444 CC.)?

Por la primera alternativa depone el artículo 39 de la ley que incorpora la existencia del premio en la definición misma del contrato. Por la segunda están los hechos de que con la supresión del premio: $i$ ) no se percibe que su inexistencia impida producir efectos al contrato; ni $i$ ) que lo haga degenerar en un contrato diferente. Se añade que, de acuerdo con el artículo $12 \mathrm{CC}$., el derecho personal al premio podría ser renunciado porque la ley no prohíbe su renuncia y aquél solo mira al interés individual del renunciante. En realidad, la mención del premio en el artículo 39 de la ley debe ser mirada como la manifestación de una presunción simplemente legal de que, en el silencio de las partes, el prestatario queda obligado a pagar el premio al prestamista; así que aquél es un elemento de la naturaleza del contrato y no de su esencia.

Por consiguiente, el préstamo de valores puede ser bien oneroso, cuando las partes guardan silencio en torno al premio y también cuando lo establecen positivamente; bien gratuito, cuando expresan su exclusión ${ }^{5}$.

\section{El préstamo de valores es un contrato conmutativo.}

El préstamo oneroso de valores es conmutativo y no aleatorio.

La definición legal del contrato conmutativo ofrecida en el artículo 1441 CC. es sumamente viciosa ${ }^{6}$, entre otras cosas porque supone que él es siempre bilateral $^{7}$, de modo de no poder haber contratos unilaterales conmutativos. Lo cual es falso, porque un contrato según el cual tan solo una parte resulte obligada y sea, por ende, unilateral, puede ser oneroso -como el mutuo con intereses- y eso es suficiente para investigar si sea conmutativo o aleatorio, debido a que esta clasificación es propia de los contratos onerosos, como lo reconoce el propio artículo $1441 \mathrm{CC}$.

El préstamo oneroso de valores, vale decir, con premio, es conmutativo en cuanto, en el momento de la perfección del contrato, ambas partes están en condiciones de "apreciar, estimar o valorar los resultados económicos" que

${ }^{5}$ Se puede preguntar por el sentido que ofrecería un préstamo gratuito de valores para el prestamista. Reconociendo que su práctica no será frecuente, podemos imaginar casos en que el prestamista prefiera no exigir un premio, como si espera reciprocidad en el futuro, cuando sea él quien solicite un préstamo al colega al que ahora presta sin premio. Gratuidad no significa necesariamente desinterés ni altruismo.

${ }^{6}$ Sobre el particular, véase: López SANT A María, Jorge, Los contratos. Parte general ( $5^{\text {a }}$ edición, Santiago, Abeledo Perrot - LegalPublishing, 2010), pp. 909-97.

${ }^{7}$ El citado artículo dice que el contrato oneroso es conmutativo cuando, en síntesis, cada una de las partes se obliga en términos equivalentes a lo que la otra se obliga, como, pues, si tenga que ser bilateral. 
aquél les originará ${ }^{8}$, comparando los dos gravámenes que contiene, de dar los valores y de pagar el premio. Los resultados económicos del contrato, pues, no dependen del azar, vale decir, no consisten en una contingencia incierta de ganancia o pérdida, como acaece en los aleatorios.

Es ajena a la calificación de conmutativo que damos a nuestro contrato, la posibilidad de resultados que derivan de situaciones como las que ofrece el siguiente análisis: Un prestamista da cierta cantidad de valores cuyo tantumdem el prestatario debe restituir en un tiempo posterior. Entretanto puede acaecer que los valores prestados incrementen su precio en el mercado o, si el precio no muda, que éste sufra los efectos de la inflación. Supóngase, por ejemplo, que el prestamista da 100 acciones de la compañía A al prestatario, que en el momento de la dación valen 10 cada una de guisa que en total ascienden a 1.000, para ser devueltas en un momento posterior; y que el premio es de 100. Llegado el momento de devolución pactado, el prestatario cumple su obligación si restituye 100 acciones de la compañía A al prestamista. Supuesto que el prestatario dispuso de las acciones recibidas, como es su facultad y seguramente necesidad, si acaeció que entre el momento de la dación y el de la restitución las acciones de la compañía A subieron su precio a 20, entonces la devolución le implica una pérdida de 1.000 , porque la compra de 100 acciones destinadas a la restitución vale 2.000; si, en cambio, éstas bajaron su precio a 5, la compra en función restitutoria le cuesta solo 500, así que gana 500. A la inversa, unos resultados adversos como los descritos no se dan en los siguientes casos: $i$ ) cuando los valores de hecho no sufren variaciones en su precio; ii) o si por su naturaleza no están sujetos a alzas o bajas de incierta predicción (como puede ser el caso de los instrumentos de renta fija ${ }^{9}$ ); iii) o en el caso en que el prestatario no necesita disponer de los valores para suplir la necesidad que tuvo de ellos, como si los pidió para darlos en garantía prendaria y, cesada aquélla, los recupera y devuelve al prestamista, pues entonces las alzas o bajas en el precio que los valores hubieran experimentado no determinan ningún evento incierto de ganancia o pérdida para el prestatario.

Ahora bien, este tipo de resultados no se toma en cuenta para pronunciar un juicio de conmutatividad o aleatoriedad del préstamo de valores, porque derivan, no de comparar las contraprestaciones de las partes (dación de los valores y premio) sino de comparar el precio de los valores recibidos con el de los restituidos. De acuerdo con el primer criterio, que es el único que

${ }^{8}$ López Santa María, J., Los contratos, cit. (n. 5), p. 91.

${ }^{9} \mathrm{La}$ rentabilidad de tales instrumentos, montada sobre la base de su reajuste más un interés anual, es conocida de antemano. Otra cosa es que ellos puedan circular en el mercado secundario a precios variables. 
debe tomarse en cuenta en esta materia, el préstamo de valores es en todo caso conmutativo.

\section{Otros rasgos del préstamo de valores en cuanto contrato.}

a) El préstamo de valores, sin discusión, es principal y no accesorio, pues subsiste por sí mismo sin necesidad de otra convención sustentante (artículo 1442 CC.). Por lo mismo admite ser garantizado con fianzas, prendas (con y sin desplazamiento) o hipotecas y por cualquiera otra caución.

b) Puesto que este contrato ha sido definido y regulado por el título $6^{\circ}$ de la Ley $\mathrm{N}^{\circ} 20.345$, él pertenece a la clase de los contratos típicos a veces también llamados "nominados". Mientras fue practicado antes de promulgada esa ley pertenecía, en cambio, a la clase de los atípicos o innominados.

c) El préstamo de valores es de aquellos llamados de ejecución (entendida como consumación) diferida, categoría ésta intermedia entre los de ejecución instantánea y los de tracto sucesivo. Aunque no pertenezca a su esencia, entre la recepción de los valores en préstamo por el prestatario y su devolución al prestamista, ha de transcurrir un lapso de tiempo, cuyo máximo el artículo $40 \mathrm{~N}^{\circ} 2$ encarga fijar (en abstracto) a los "sistemas" por medio de sus normas de funcionamiento. Si las partes no fijan un concreto plazo de restitución, rige lo dispuesto por el artículo 2200 CC. (o por el artículo 795 CCom.): el prestamista no puede exigir la devolución de los valores antes de corridos 10 días desde la transferencia. De esta forma, aún en el peor de los casos este contrato se consuma diferidamente después de esos 10 días y nunca instantáneamente.

d) El préstamo de que tratamos es un contrato definitivo y no preparatorio de otro, aunque pueda servir a otro, lo que es muy distinto ${ }^{10}$; pero admite ser preparado el mismo merced a una previa promesa de contrato o de una opción, que deben someterse a las reglas generales.

\section{El DERECHO PRINCIPAL Y EL SUBSIDIARIO DEL PRÉSTAMO DE VALORES}

1. El contrato de préstamo de valores queda sometido a un Derecho complejo, integrado por los siguientes estratos: $i$ ) como Derecho principal, por las normas del título $6^{\circ}$ de la Ley No 20.345; ii) como Derecho supletorio

\footnotetext{
${ }^{10} \mathrm{El}$ prestatario suele pedir valores prestados para con ellos poder cumplir obligaciones de darlos que han emanado de otro contrato. Esa circunstancia no determina ningún régimen especial aplicable al préstamo de valores. Para el prestatario, el cumplimiento de otros contratos opera como motivo (no, por cierto, como causa) para celebrar el préstamo; $y$, como es sabido, por regla general los motivos son irrelevantes, a menos que se los introduzca como condición o modo en el acto motivado.
} 
de primer grado, por las normas de funcionamiento para la realización de operaciones de préstamo de valores, merced a lo dispuesto por el inciso $1^{\circ}$ del artículo 40 de la misma ley; iii) como Derecho supletorio de segundo grado, por las normas del Código Civil sobre mutuo (principalmente contenidas en el título $31^{\circ}$ del libro IV CC.) si el acto no es de comercio; o del título $13^{\circ}$ del libro II del Código de Comercio, sobre préstamos, si lo es; y iv) cuando los valores prestados consistan en documentos representativos de obligaciones de dinero pagaderos a la vista, a un plazo contado desde la vista o a un plazo determinado, entonces actúa como Derecho supletorio de tercer grado la Ley No 18.010 de 1981.

Lo expresado sobre el Derecho principal se explica por sí solo.

a) En lo concerniente al Derecho supletorio de primer grado, cabe examinar el inciso $1^{\circ}$ del artículo 40 de la Ley $\mathrm{N}^{\circ} 20.345$, que expresa: "Los sistemas establecerán normas para la realización de operaciones de préstamo de valores, las cuales contendrán a lo menos las siguientes materias:/ [...]".

La expresión "normas" debemos entenderla como referida a las que define el artículo $1 \mathrm{~N}^{\circ} 2$ de la Ley $\mathrm{N}^{\circ} 20.345$ : "Para efectos de lo dispuesto en la presente ley, se entenderápor:/ [...]/2. Normas defuncionamiento: las normas que regulan la incorporación de participantes a un sistema y su operación". Como las normas aludidas en el inciso $1^{\circ}$ del artículo 40 de la ley citada son para la realización de operaciones de préstamo de valores, y eso queda abrazado por cobertura propia de las normas de funcionamiento en cuanto ellas regulan la operación de los participantes en un sistema, es claro que las "normas para la realización de operaciones de préstamo de valores" mentadas por el inciso $1^{\circ}$ del artículo 40 tienen la naturaleza de normas de funcionamiento de las definidas en el $\mathrm{N}^{\circ} 2$ del artículo 1 de la ley.

El nombre de "sistema" usado en plural por el inciso $1^{\circ}$ del artículo 40 es abreviación de "sistema de compensación y liquidación de instrumentos financieros”, y a él se refiere el artículo $1 \mathrm{~N}^{\circ} 1$ de la Ley $\mathrm{N}^{\circ} 20.345$ en estos términos: "Para efectos de lo dispuesto en la presente ley, se entenderá por: 1. Sistema de compensación y liquidación de instrumentos financieros, en lo sucesivo "sistema": el conjunto de actividades, acuerdos, participantes, normas, procedimientos y mecanismos que tengan por objeto compensar y liquidar órdenes de compensación". Es evidente, empero, que los "sistemas" así definidos difícilmente pueden llegar a tener cierta unitaria personificación que les permita emitir normas de manera organizada, así que la noción de que sean los "sistemas" los encargados de emitir las normas de funcionamiento en general y relativas a los prestamos en especial mejor resulta ser competencia de una sociedad administradora. Por tal se entiende, según el artículo $1 \mathrm{~N}^{\circ}$ 3 de la Ley $\mathrm{N}^{\circ} 20.345$ a la "persona jurídica a cargo de la dirección y operación de un sistema, cuya constitución y operación se rige por la presente ley y por sus 
normas". Y es evidente que ahora se cumple con el presupuesto que hace posible que ciertas normas sean emitidas; por esto interpretamos que, en realidad, no son los sistemas, sino sus sociedades administradoras las habilitadas para emitir normas de funcionamiento de los sistemas.

De estas sociedades, la ley distingue dos especies ${ }^{11}$ : la "entidad de contraparte central" destinada a gestionar órdenes de compensación constituyéndose en acreedora y deudora de los derechos y obligaciones que deriven de tales órdenes (artículo $1 \mathrm{~N}^{\circ} 4$ ); y la "cámara de compensación de instrumentos financieros", que gestiona órdenes de compensación sin constituirse en contraparte central de las mismas (artículo $1 \mathrm{~N}^{\circ} 5$ ).

Así que, en síntesis, las sociedades administradoras de los sistemas de compensación y liquidación de instrumentos financieros son competentes para emitir normas para el funcionamiento de tales sistemas, entre las cuales están aquellas destinadas a regular la realización de operaciones de préstamo de valores. Por consiguiente estas normas constituyen el Derecho supletorio de primer grado de la ley en cuanto a esa materia.

b) Por lo que atañe al Derecho supletorio de segundo grado, el argumento se desarrolla de la siguiente manera:

En rigor, el préstamo de valores regulado en el título $6^{\circ}$ de la Ley $\mathrm{N}^{\circ}$ 20.345 no es un contrato ni nuevo ni especial, sino una aplicación del mutuo o préstamo de consumo definido así por el artículo 2196 CC.: "El mutuo o préstamo de consumo es un contrato en que una de las partes entrega a la otra cierta cantidad de cosas fungibles con cargo de restituir otras tantas del mismo género y calidad". Lo esencial en esta figura es la transferencia ${ }^{12}$ de una cantidad de cosas fungibles para que se devuelva no las mismas especies, sino otro tanto idéntico del mismo género y calidad (tantumdem eiusdem generis et qualitatis). Pero la ley no la circunscribe a las cosas corporales (pues se limita a decir "cosas" en general), así que nada obsta a que alguien ceda, es decir, transfiera a otro una cierta cantidad de cosas incorporales (transferibles) que las partes consideren fungibles, como los créditos de dinero ${ }^{13}$, con cargo a que

\footnotetext{
${ }^{11}$ Cfr. con el artículo 4 de la Ley $\mathrm{N}^{\circ} 20.345:$ "La administración de sistemas de compensación y liquidación de instrumentos financieros sólo podrá ser ejercida por sociedades administradoras constituidas como entidades de contraparte central o cámaras de compensación de instrumentos financieros de conformidad a la presente ley". En esta norma está claramente delimitada la relación de género a especie entre los entes de que tratamos.

${ }^{12} \mathrm{El}$ artículo transcrito dice que el mutuo consiste en una "entrega"; pero en realidad consiste en una "tradición", vale decir, en una transferencia, como lo expresa el artículo 2197 CC.: "No se perfecciona el contrato de mutuo sino por la tradición, y la tradición transfiere el dominio"; y reconoce la unanimidad de la doctrina.

${ }^{13}$ Se puede sostener que un crédito de dinero es no fungible atendida la determinación e individualización del acreedor y del deudor, lo cual es verdadero; pero este rasgo desaparece si las partes lo miran como fungible y el prestamista está dispuesto a
} 
el accipiens le restituya después otro tanto de las mismas ${ }^{14}$. La situación no cambia si en vez de un crédito referimos la figura a un valor, sea titulado, sea desmaterializado, que después de todo en la mayoría de los casos es un crédito, como, por ejemplo unas acciones, que se transfieren para que el adquirente devuelva otro tanto del mismo género, o sea, de la misma compañía emisora (y de la misma clase y serie si es el caso). Y en esto consiste el préstamo de valores regulado en el título $6^{\circ}$ de la Ley $\mathrm{N}^{\circ} 20.345$. En cuanto a la onerosidad o gratuidad de ambos contratos tampoco hay diferencias. El mutuo puede ser oneroso o gratuito, esto es, con o sin intereses, aunque la gratuidad no se presume en las operaciones de crédito de dinero ${ }^{15}$ (y no, desde luego, en los préstamos mercantiles: artículo 798 CCom.), lo que significa que en el silencio sobre la materia se lo considera oneroso. Por lo que toca al contrato de préstamo de valores, como ya quedó establecido, él también puede ser oneroso o gratuito; así que no hay diferencias al respecto.

Ahora bien, si el préstamo de valores no es otra cosa que una aplicación del mutuo, entonces, cuando el préstamo de valores de que se trate sea civil, las reglas del Código Civil relativas a este último contrato (principalmente contenidas en el título $31^{\circ}$ de su libro IV) constituyen el Derecho supletorio (de segundo grado) del título $6^{\circ}$ de la Ley $\mathrm{N}^{\circ} 20.345$; y de ser comercial, el Derecho supletorio de segundo grado está representado ahora por las reglas sobre el préstamo que es como el Código de Comercio denomina al mutuo mercantil, regulado principalmente en el título $13^{\circ}$ del libro II de ese cuerpo legal.

c) Pero puede acaecer que los valores prestados consistan en documentos representativos de obligaciones de dinero pagaderos a la vista, a un plazo contado desde la vista o a un plazo determinado; y en este caso, y solo en él,

que le fuere devuelto cualquier otro crédito cuyo acreedor sea el prestatario y el deudor otro individuo quienquiera que sea. Si esto es cierto para los créditos de dinero lo es también para los créditos sobre fungibles que no sean dinero. La fungibilidad de que hablamos es exigible entre el crédito prestado y el recibido (porque se debe cumplir con que lo devuelto sea del mismo género al de lo recibido); no basta, pues, que ambos sean fungibles en abstracto si no lo son entre sí. Advertimos esto porque el préstamo de un fungible para recibir otro no es préstamo sino permuta, como cuando se dice: te doy 1.000 quintales de trigo para que me devuelvas 1.000 botellas de tal vino, pues, aunque el trigo y tal vino son fungibles en abstracto no lo son entre sí.

${ }^{14}$ Añádase que la Ley $\mathrm{N}^{\circ} 18.010$, de 1981: Sobre operaciones de crédito de dinero (DO. de 27 de junio de 1981), considera tales al "descuento de documentos representativos de dinero" (artículo 1 inciso $2^{\circ}$ ), teniendo presente que el "descuento" no es otra cosa que una cesión del crédito que se descuenta; y además ella asimila al dinero "los documentos representativos de obligaciones de dinero pagaderos a la vista, a un plazo contado desde la vista o a un plazo determinado" (artículo 1 inciso $3^{\circ}$ ).

${ }^{15}$ Ley $\mathrm{N}^{\circ} 18.010$ de 1981, artículo 12. 
la Ley $\mathrm{N}^{\circ}$ 18.010: que Establece normas para las operaciones de crédito y otras obligaciones de dinero (DO. de 27 de junio de 1981) también constituye Derecho supletorio, pero de tercer grado, del contrato en examen, por disposición del inciso $3^{\circ}$ del artículo 1 de esa misma ley, el cual dispone considerar como dinero a los dichos documentos ${ }^{16}$, de modo que su préstamo es operación de crédito de dinero que cae bajo la potestad de aquella ley.

d) Para no hacer aun más complejo un punto que ya lo es excesivamente, me limito a señalar en último lugar, aunque ocupa el primero, algo sobreentendido, a saber, que el préstamo de valores queda sometido al Derecho común y general de los actos, contratos y negocios jurídicos y de las obligaciones.

\section{SuJETOS DEL PRÉSTAMO DE VAlORES}

El préstamo de valores regulado en el título $6^{\circ}$ de la Ley $\mathrm{N}^{\circ} 20.345$ tiene como sujetos a los intervinientes en los sistemas de compensación y liquidación de instrumentos financieros regidos por esa misma ley, según la distribución que pasamos a exponer:

\section{Sujetos prestatarios.}

Solo pueden actuar como prestatarios los participantes en dichos sistemas, es decir, las personas que enumera como tales el artículo 21, a saber: los agentes de valores, los corredores de bolsas de valores, los corredores de bolsas de productos, los bancos y las demás personas que autorice la Superintendencia a través de normas de carácter general ${ }^{17}$.

${ }^{16}$ Ley $\mathrm{N}^{\circ} 18.010$, artículo 1: "[Inciso $1^{\circ}$ ] Son operaciones de crédito de dinero aquéllas por las cuales una de las partes entrega o se obliga a entregar una cantidad de dinero y la otra a pagarla en un momento distinto de aquel en que se celebra la convención./ [Inciso $2^{\circ}$ ] Constituye también operación de crédito de dinero el descuento de documentos representativos de dinero, sea que lleve o no envuelta la responsabilidad del cedente./ [Inciso $3^{\circ}$ ] Para los efectos de esta ley, se asimilan al dinero los documentos representativos de obligaciones de dinero pagaderos a la vista, a un plazo contado desde la vista o a un plazo determinado./ [Inciso $4^{\circ}$ ] No se aplicarán las disposiciones de este Título a las operaciones de crédito de dinero correspondientes a contratos aleatorios, arbitrajes de monedas a futuro préstamo marítimo o avio minero". Por supuesto, la moneda nacional no es considerada como valor y su préstamo es directamente un mutuo normal (inciso $\left.1^{\circ}\right)$. El descuento de documentos representativos de dinero (inciso $2^{\circ}$ ) es en sí una operación distinta a su préstamo.

${ }^{17}$ Así, por ejemplo, mediante una Norma de carácter general № 293, de 14 de octubre de 2010, la Superintendencia tiene autorizadas a las bolsas de valores para actuar como participantes de sistema de compensación y liquidación de instrumentos financieros. 
Que sea así como lo hemos afirmado no lo dice ninguna norma expresamente; pero de manera indirecta se deduce de varias de la Ley $\mathrm{N}^{\circ} 20.345$, que transcribiremos y comentaremos en sus partes pertinentes: $i$ ) el artículo 2: "La presente ley se aplicará a los sistemas de compensación y liquidación de instrumentos financieros, a las sociedades administradoras y sus participantes, a las garantias otorgadas por estos últimos y [...]": la norma supone que los participantes otorgan garantías; ahora bien, un caso en que las hay es precisamente el del préstamo de valores y en el cual solo el prestatario podría conferirlas, de modo que éste tiene que ser un participante; ii) el artículo 7: "[Inciso $1^{\circ}$ ] Las sociedades administradoras deberán presentar a la Superintendencia las normas de funcionamiento y un estudio tarifario de cada uno de los sistemas que administren./ [Inciso $2^{\circ}$ ] Todo sistema deberá contar con normas de funcionamiento que contemplen, a lo menos, las siguientes materias: / [...] 8. Las garantias que deberán ser proporcionadas por los participantes, asi como la [...]": en las normas de funcionamiento deben regularse, entre otras materias, la de las garantías conferibles por los participantes; pero cuando se trate de las garantías del cumplimiento de préstamos de valores, las únicas garantías posible son las que otorga el prestatario, que, por ende, tiene que ser un participante; iii) el artículo 13: "Para el desarrollo de su objeto, las contrapartes centrales realizarán las siguientes actividades:/ [...]/2. Requerir, recibir, administrar y realizar garantías para asegurar el cumplimiento de las obligaciones de los participantes, [...]": nuevamente se supone que los participantes dan garantías para asegurar el cumplimiento de sus obligaciones; pero en materia de préstamos de valores el único que puede dar garantías es el prestatario, que, por ende, va considerado como participante; iv) el artículo 26: "Las sociedades administradoras deberán requerir garantias a los participantes para asegurar el cumplimiento de las obligaciones que éstos asuman o que se deriven del ingreso de órdenes de compensación al sistema": nuevamente debe decirse que el prestatario de un préstamo de valores, único que da garantías en el caso de este contrato, está incluido bajo el concepto de obligaciones asumidas por los participes.

La ley, por consiguiente, aunque no declara expresamente que el prestatario deba ser un participante en el sistema, da por supuesto que siempre lo es.

\section{Sujetos prestamistas.}

Pueden actuar como prestamistas en nuestro contrato los participantes en los sistemas de compensación y liquidación de instrumentos financieros, es decir, las personas que enumera como tales el artículo 21, ya dichos en la letra anterior, que, por ende, pueden prestarse valores entre sí; y también las sociedades administradoras de sistemas que consistan en entidades de contra- 
parte central. Así lo dice expresamente el artículo 13: "Para el desarrollo de su objeto, las contrapartes centrales realizarán las siguientes actividades:/ [...]/ 4. Efectuar aquellas operaciones de compraventa de instrumentos financieros, de préstamo de valores y de financiamiento, que sean necesarias para el cumplimiento de sus funciones".

\section{OBjeto DEL PRÉSTAMo de VALORES}

1. El contrato recae necesariamente sobre objeto que consistan en "valores". El artículo 39 de la Ley $\mathrm{N}^{\circ} 20.345$, en efecto, al definir el contrato, dice que en su virtud cierto prestamista transfiere "valores" a un prestatario, quien asume la obligación de restituir al primero también "valores" del mismo emisor, género, cantidad, clase y serie al de los recibidos.

Por cuanto respecta al concepto de "valor", disponemos de dos normas. Por un lado se presenta el artículo 1 de la Ley $\mathrm{N}^{\circ} 20.345$, que expresa: "Para efectos de lo dispuesto en la presente ley, se entenderá por: [ [...]/ 8. Instrumentos financieros: valores de conformidad a lo establecido en el articulo $3^{\circ}$ de la ley $N^{o}$ 18.045, sobre Mercado de Valores y, en general, cualquier titulo, derecho, acto, contrato, factura, producto o moneda extranjera, negociables en mercados nacionales o extranjeros. En todo caso, se excluye la moneda nacional". Por otro está el artículo 3 de la Ley $\mathrm{N}^{\circ}$ 18.045: De mercado de valores (DO. de 21 de octubre de 1981), al que el artículo recién transcrito se remite, que establece: "[Inciso $1^{\circ}$ ] Para los efectos de esta ley, se entenderá por valores cualesquiera titulos transferibles incluyendo acciones, opciones a la compra y venta de acciones, bonos, debentures, cuotas de fondos mutuos, planes de aborro, efectos de comercio $y$, en general, todo título de crédito o inversión./ [Inciso $2^{\circ}$ ] Las disposiciones de la presente ley no se aplican a los valores emitidos o garantizados por el Estado, por las instituciones públicas centralizadas o descentralizadas y por el Banco Central de Chile".

Pese a la apariencia contraria que ofrecen estas normas, no existe sinonimia entre las nociones de "instrumento financiero" y "valor". La relación entre ambas puede establecerse así: todo valor es un instrumento financiero; pero no todo instrumento financiero es un valor. La definición de "instrumento financiero" contenida en el artículo $1 \mathrm{~N}^{\circ} 8$ de la Ley $\mathrm{N}^{\circ} 20.345$ incluye a todos los valores, no solo por su remisión al artículo 3 de la Ley $\mathrm{N}^{\circ} 18.045$, que los define, sino porque expresamente atañe "en general" a cualquier título negociable, derecho negociable, acto negociable, contrato negociable y factura negociable ${ }^{18}$, con lo cual, en principio, aun nos mantenemos en el ámbito de los valores. Pero entre los instrumentos financieros la norma también incluye

${ }^{18} \mathrm{El}$ adjetivo "negociable” en plural abraza a todos los sustantivos que lo preceden. 
los "producto negociables" (como los "commodities": oro, plata, diamantes, petróleo, cobre, etc. $)^{19}$ y la "moneda extranjera negociable". Ahora bien, los productos y la moneda (extranjera o no) no son valores en el sentido del artículo 3 de la Ley $\mathrm{N}^{\circ}$ 18.045. De donde la aludida mayor extensión del concepto de "instrumento financiero" respecto del de "valor".

Ahora bien, el contrato en examen recae no sobre "instrumentos financieros" sin más, sino, como quedó dicho al principiar, sobre valores. Se puede decir lo mismo expresando que recae sobre instrumentos financieros que sean valores. De ahí que en este punto tenga primacía el artículo 3 de la Ley $\mathrm{N}^{\circ} 18.045$. La definición del artículo $1 \mathrm{~N}^{\circ} 8$ de la Ley $\mathrm{N}^{\circ} 20.345$ en cuanto también añade en general, "cualquier título, derecho, acto, contrato, factura, producto o moneda extranjera, negociables en mercados nacionales $o$ extranjeros" vale a efectos de determinar el objeto del préstamo solo en cuanto el ítem incluido ahí admita ser calificado de "valor". Como ya quedó dicho, los productos y las monedas extranjeras negociables no admiten tal calificación, y seguramente tampoco algunos derechos, actos y contratos. Por disposición expresa del mismo artículo $1 \mathrm{~N}^{\circ} 8$ también queda excluida la moneda nacional. El inciso $2^{\circ}$ del artículo 3 de la Ley $\mathrm{N}^{\circ} 18.045$ excluye a los valores emitidos o garantizados por el Estado, por las instituciones públicas centralizadas o descentralizadas y por el Banco Central de Chile.

2. Pero lo dicho con agota la delimitación del objeto del préstamo de valores, porque el artículo $40 \mathrm{~N}^{\circ} 1$ de la Ley $\mathrm{N}^{\circ} 20.345$ dispone: "Los sistemas establecerán normas para la realización de operaciones de préstamo de valores, las cuales contendrán a lo menos las siguientes materias:/ 1. Los valores quepodrán ser objeto de tales operaciones, los cuales deberán encontrarse libres de todo tipo de gravamen, carga, embargo o probibición". De acuerdo con esta norma, pues, no basta con que el contrato recaiga sobre un valor para ser válido, y también es menester que el valor sobre el cual haya de recaer deba haber sido previamente declarado como objeto posible del contrato en las normas de funcionamiento establecidas por los sistemas. Si determinados valores no han sido declarados tales, no puede celebrarse préstamo sobre ellos.

El préstamo sobre valores inidóneos es nulo absolutamente, porque el requisito ha sido establecido en consideración a la naturaleza del acto y no a la calidad o estado de las personas (artículo $1682 \mathrm{CC}$.)

${ }^{19}$ La expresión "producto negociable" no atañe a valores que tengan por objeto subyacente cosas corporales como las opciones sobre "commodities", sino a las cosas corporales subyacentes mismas, porque la opción está definida como valor en el artículo 3 de la Ley No 18.045 y aunque no mencionadas expresamente, caben en el artículo 1 de la Ley Na 23.345. 
3. El artículo 38 de la ley expresa: "[Inciso $1^{\circ}$ ] Con el objeto de asegurar el correcto funcionamiento del sistema, las Cámaras de Compensación o de Contrapartes Centrales y las empresas de depósito de valores reguladas por la ley $N^{\circ}$ 18.876, podrán establecer un registro de préstamo de valores en el cual se anotarán los valores disponibles para ser prestadosy [...]./ [Inciso $2^{\circ}$ ] Las sociedades administradoras podrán encargar a las empresas de depósito de valores regidas porla ley $N^{\circ} 18.876$, el registro establecido en el inciso anterior" . En los registros de préstamos de valores establecidos por las sociedades administradoras (o sea, por cámaras de compensación o por entidades de contraparte central ${ }^{20}$ ) o bien por las empresas de depósito de valores regidas por la Ley $\mathrm{N}^{\circ} 18.876$ por encargo de aquéllas, o por estas mismas empresas de depósito de valores por sí mismas, pueden anotarse los valores disponibles para ser prestados. A diferencia del requisito de estar un valor declarado "prestable" en las normas de funcionamiento que establecen los sistemas, esta anotación de valores en los mencionados registros carece de sanción: no es requisito para la validez de un préstamo, ni formalidad de publicidad destinada a fundar oponibilidad. Su función solo es facilitar de hecho los préstamos, merced a la difusión de la circunstancia de que tales y cuales valores se encuentran disponibles para ser prestados, porque quienes buscan valores para solicitarlos en préstamo no tiene medios formales para conocer cuáles están disponibles al efecto. Como lo dice el encabezamiento de la norma, este método está dirigido a asegurar el correcto funcionamiento del sistema, no su validez.

\section{LEGITIMACIÓN PARA PRESTAR VALORES}

1, En materia de legitimación para prestar valores, el inciso final del artículo 40 de la Ley $\mathrm{N}^{\circ} 20.345$ prescribe: "Sólo podrán prestar valores [...] quienes sean los dueños de los valores respectivos o sus representantes". El original artículo 42 del proyecto del Ejecutivo introducía la legitimación dominical en la definición misma del contrato, pues del préstamo de valores decía ser "un contrato en virtud del cual una persona, llamada prestamista, transfiere valores de su propiedad a otra, llamada prestatario [...]"21. Por indicación presidencial, la expresión "de su propiedad" fue eliminada de la definición ${ }^{22}$, tal vez porque ya el texto original contenía el siguiente inciso final en su artículo 43: "Solo podrá prestar valores u otorgar garantías respecto de tales

\footnotetext{
${ }^{20} \mathrm{La}$ norma parece considerar posible denominarlas "cámaras de contraparte central" porque dice: "las cámaras de compensación o [las cámaras] de contrapartes centrales", pero el artículo $1 \mathrm{~N}^{\circ} 4$ las llama "entidades de contraparte central"; pero pertenecen al género de las sociedades de administración, igual que las cámaras de compensación.

${ }^{21}$ Historia de la ley 20.345 (Biblioteca del Congreso Nacional), p. 28.

${ }^{22}$ Historia, cit. (n. 15), p. 265.
} 
operaciones quienes sean los titulares de los valores respectivos" 23 , y entonces se habría considerado - con razón- que existía una redundancia normativa entre exigir la propiedad de los valores prestados en el artículo 42 y su titularidad en el 43. Merced a una nueva indicación presidencial, en este inciso se sustituyó la expresión "titulares" por "dueños" (y se añadió después de "respectivos": "o sus representantes") ${ }^{24}$; y fue así que el actual inciso final del artículo 40 adquirió su forma definitiva: "Sólo podrán prestar valores u otorgar garantías respecto de tales operaciones quienes sean los dueños de los valores respectivos o sus representantes".

En síntesis, pues, la legitimación para prestar valores pertenece exclusivamente al dueño o titular (personalmente o representado) de los valores que se trata de prestar.

2. Cuando quien los presta no sea su dueño o representante de éste, cabe preguntarse si habrá de ser considerado nulo el contrato o de ser aplicada la regla contenida en el artículo 2202 CC.: "[Inciso $1^{\circ}$ ] Si hubiere prestado el que no tenia derecho de enajenar, se podrán reivindicar las especies, mientras conste su identidad./ [Inciso $2^{\circ}$ ] Desapareciendo la identidad, el que las recibió de mala fe será obligado al pago inmediato con el máximum de los intereses que la ley permite estipular; pero el mutuario de buena fe sólo será obligado al pago con los intereses estipulados y después del término concedido en el artículo 2200 ".

La verdad es que la posibilidad de anulación del contrato contraría el modelo del Código, para el cual los actos sobre cosa ajena valen, pero no afectan la propiedad del verdadero dueño, quien siempre puede reivindicar, sin perjuicio de la prescripción adquisitiva del actual poseedor. Véase al respecto el ejemplar artículo $1815 \mathrm{CC}$. Ahora bien, el dispositivo del artículo 2202 CC., antes transcrito, es una manifestación de dicho modelo. Nos inclinamos, pues, por opinar favorablemente a su aplicación.

Para ella, se debe tener presente que cuando el valor prestado haya sido desmaterializado de modo que solo conste anotado en cuenta, siempre pierde su identidad, si es que la tuvo. Este rasgo se desprende de los artículos 4, 6 y 10 de la Ley N ${ }^{\circ} 18.876$, de 1989: que Establece el marco legal para la constitución y operación de entidades privadas de depósito y custodia de valores (DO. de 21 de diciembre de 1989). Tales normas hablan de "valores homogéneos" lo que equivale a "valores fungibles" porque por aquéllos su artículo 4 inciso $1^{\circ}$ entiende a "los que sean idénticos en cuanto a tipo, especie, clase, serie y emisor", de modo que usa los mismos conceptos que el artículo

\footnotetext{
${ }^{23}$ Historia, cit. (n. 15), p. 28.

${ }^{24}$ Historia, cit. (n. 15), p. 266.
} 
39 de la Ley $\mathrm{N}^{\circ} 20.345$ emplea para definir la que hemos denominado fungibilidad de los valores prestados con respecto a los devueltos. Del mismo modo, una vez depositados los valores bajo forma desmaterializada, pierden su individualidad, si la tuvieron, pues la empresa de depósito y custodia los anota por separado en tantas cuentas individuales para cada depositante según sean las distintas clases de valores homogéneos que aquel mantenga en depósito (artículo 4 de la Ley $\mathrm{N}^{\circ} 18.876$ ); y cuando éste cese y proceda la restitución de los valores la empresa cumple su obligación de restituirlos entregando valores homogéneos (artículo 6 de la ley citada), vale decir, no los mismos recibidos en depósito sino el tantumdem. Por consiguiente, si durante la vigencia del depósito, los valores anotados en cuenta son prestados, lo que se presta carece de individualidad y no son infungibles, de modo que si el prestamista no es su dueño siempre procede aplicar la regla del inciso $2^{\circ}$ del artículo 2202 CC., que supone la desaparición de identidad de las cosas prestadas. Por supuesto, no es la única situación en que procede aplicar esa regla; de hecho su aplicación procede toda vez que pueda apreciarse que los valores prestados perdieron su individualidad.

\section{Plazo para la Restitución de los VAlores PRESTAdos}

El artículo 39 de la Ley $\mathrm{N}^{\circ} 20.345$, que contiene, como se recordará, la definición del contrato, expresa que el prestatario asume la obligación de restituir los valores recibidos "al vencimiento del plazo pactado". Por cierto, la obligación existe desde que la transferencia de los valores al prestatario queda consumada, y el plazo solo suspende su exigibilidad; lo cual no es más que aplicación de las reglas generales que rigen el plazo.

La libertad que tienen las partes para establecer la extensión del plazo de restitución reconoce un límite fijado en el artículo $40 \mathrm{~N}^{\circ} 2$ de la ley, que dice: "Los sistemas establecerán normas para la realización de operaciones de préstamo de valores, las cuales contendrán a lo menos las siguientes materias:/ [...]/ 2. El plazo máximo para la restitución de los valores prestados, el cual no podrá ser superior al día hábil anterior a la fecha de vencimiento de los valores respectivos". La ley, pues, encarga a los sistemas que en las normas de funcionamiento que deben emitir establezcan un plazo máximo de restitución de los valores prestados. Los sistemas, a su vez, son libres para fijar la extensión de ese plazo máximo, con la limitación de no poder ser superior al día hábil anterior a la fecha de vencimiento de los valores respectivos; bajo el supuesto tácito de que los valores tengan fecha de vencimiento, como los bonos; pues si no lo tienen, como las acciones, entonces esa limitación no es aplicable.

El artículo $40 \mathrm{~N}^{\circ} 4$ de nuestra ley establece: "Los sistemas establecerán normas para la realización de operaciones de préstamo de valores, las cuales 
contendrán a lo menos las siguientes materias:/ [...]/ 4. La forma y plazo en que el prestatario reembolsaráal prestamista, el monto de los intereses, dividendoso cualesquiera otros derechos económicos que se hayan devengado en dicho lapso". El sentido del $\mathrm{N}^{\circ} 4$ se descubre cuando se modifica su texto de la siguiente manera: "La forma y <el> plazo en que el prestatario reembolsará el monto de los intereses, dividendos o cualesquiera otros derechos económicos que se hayan devengado en dicho lapso al prestamista". El plazo que se debe fijar en las normas de funcionamiento, pues, no es para la restitución de los valores recibidos, sino para el reembolso de los rubros señalados en la norma, aunque, apresuradamente leída la disposición es lo primero lo que da a entender el texto auténtico. Pero de entenderlo así, entonces queda abolida la diferencia entre restitución y reembolso, por un lado; $y$, por otro, la idea de que el plazo de restitución de los valores queda entregado al libre pacto de las partes, como dice el artículo 39 (con la limitación señalada en el artículo $40 \mathrm{~N}^{\circ} 2$, ya vista) resultaría contradicha por esta otra de que las normas deben ellas mismas fijar el plazo de restitución.

En síntesis, pues, el plazo que las normas de funcionamiento deben fijar en seguimiento del artículo $40 \mathrm{~N}^{\circ} 4$ no atañe a la restitución de los valores prestados, sino al reembolso de los intereses, dividendos o cualesquiera otros derechos económicos que se hayan devengado "en dicho lapso". En el capítulo que sigue nos referiremos por separado a este reembolso.

\section{REEMBOLSO DE LOS INTERESES, DIVIDENDOS Y OTROS} EMOLUMENTOS DEVENGADOS A PARTIR DE LOS VALORES PRESTADOS MIENTRAS ESTUVIERON EN TAL CONDICIÓN

1. Comparece nuevamente el artículo $40 \mathrm{~N}^{\circ} 4$ de la Ley $\mathrm{N}^{\circ} 20.345$, cuyos términos volvemos a transcribirlos por comodidad del lector: "Los sistemas establecerán normas para la realización de operaciones de préstamo de valores, las cuales contendrán a lo menos las siguientes materias:/ [...]/ 4. La forma y $<$ <l> plazo en que el prestatario reembolsará al prestamista, el monto de los intereses, dividendos o cualesquiera otros derechos económicos que se hayan devengado en dicho lapso".

De acuerdo con la interpretación que hemos dado a este precepto, la forma y el plazo que las normas de funcionamiento deben establecer se refieren al reembolso de los dividendos, intereses y otros emolumentos devengados "en dicho lapso" y no a la restitución de los valores prestados, que es materia regulada en el artículo $40 \mathrm{~N}^{\circ} 2$.

Pero la expresión "en dicho lapso" no tiene referencia clara; lo más probable es que ella sea al "plazo" que las normas de funcionamiento deben fijar para el reembolso de los rubros detallados en el $\mathrm{N}^{\circ} 4$. De esta manera, el artículo 
$40 \mathrm{~N}^{\circ} 4$ obliga a que los sistemas fijen en sus normas de funcionamiento un plazo de reembolso de los emolumentos señalados en ella misma; y este plazo parece ser único e inflexible.

2. La ley, pues, dispone de un modo incidental, al referirse a un punto accesorio como es el plazo, sobre un tema sustantivo de gran importancia en la figura del préstamo de valores. Puesto que dicho préstamo consiste en una transferencia de los valores prestados al prestatario, resulta que éste se hace dueño de ellos. Como los emolumentos generados por los valores pertenecen a su dueño, es consecuente que tales emolumentos pertenezcan, una vez devengados, al prestatario, en su calidad de actual dueño de los valores productores. Pero aunque así sea, la adquisición de tales emolumentos es crediticia igual que la adquisición de los valores que los generan; es decir, los aludidos emolumentos, igual que esos valores, pertenecen al prestatario, pero los debe al prestamista. No hay razón para atribuir definitivamente la propiedad de esos emolumentos al prestatario; por consiguiente, en algún instante debe transferirlos al prestamista; esta transferencia es definida con recurso al verbo "reembolsar" por el artículo $40 \mathrm{~N}^{\circ} 4$.

Ahora bien, lo lógico es que este reembolso tenga lugar simultáneamente con la restitución. No se divisa razón alguna para que se la ejecute con anterioridad; y menos razón hay para que se la ejecute con posterioridad. Esto significa que el plazo para el reembolso debería coincidir con el plazo para la restitución. Pero es en este punto en que la ley introduce un principio de incongruencia. Por un lado, ella, según vimos, deja librada la extensión del plazo de restitución a la libertad de las partes (con una limitación ya vista); por otro, ordena que sean las normas de funcionamiento del sistema las que fijen el plazo para el reembolso; $y$, al parecer, este plazo es único y rígido. Pero bien puede darse que el plazo de restitución libremente pactado sea menor o mayor que el de reembolso normativamente fijado; y en tales hipótesis acaecerá que se priva al prestatario que reembolsó pero al cual aun no le es exigible la restitución, de los emolumentos generados con posterioridad; o bien que haya restituido y aun le reste plazo para el reembolso, sin que realmente haya razón sustantiva para el que aprovecha los emolumentos cuando el préstamo ya se extinguió.

Es, por consiguiente, aconsejable que las normas de funcionamiento establezcan como plazo de reembolso "el plazo de restitución que fijen en cada caso las partes".

Va de suyo, empero, que cuando se configure la incongruencia anotada, eso no influye en el reembolso; porque si el plazo para éste es mayor que el de restitución, los emolumentos devengados después de todos modos tienen que ser restituidos junto con los devengados antes; y si el plazo de reembolso es 
menor que el de restitución, una vez llegado aquél y producido el reembolso, igual el prestatario adquiere los emolumentos posteriores, que, por cierto, deberá reembolsar esta vez junto con la restitución, todo de acuerdo con las reglas generales sobre enriquecimiento sin causa.

3. Los emolumentos nominativamente indicados por la ley son los intereses y los dividendos. Bajo los primeros se refiere a los generados por valores crediticios, como los bonos o cualquier otro valor representativo de una deuda. Bajo los segundos se refiere a los emolumentos generados por las acciones. Pero añade en seguida: "o cualesquiera otros derechos económicos que se hayan devengado". No fue muy arreglado usar el término "derechos", porque si bien haya un derecho a los intereses o un derecho a los dividendos, no es el derecho el devengado, percibido y reembolsado, sino el emolumento generado por el ejercicio de ese derecho, que generalmente consiste en dinero. Lo que se rembolsa, pues, es el dinero si fue dinero lo que se percibió, no el derecho. En todo caso, la ley considera reembolsable no solo el dinero de los intereses y de los dividendos, sino lo devengado por cualquier otro título. Un ejemplo puede ser el de las acciones de pago, vale decir, las que una sociedad anónima reparte a prorrata entre sus accionistas cuando se abstiene de distribuir las ganancias y prefiere capitalizarlas. Si el prestatario, pues, recibió tales acciones -llamadas “crías” en la jerga bursátil-, debe reembolsarlas al prestamista.

4. El artículo $40 \mathrm{~N}^{\circ} 4$ autoriza a los sistemas para establecer en sus normas de funcionamiento la "forma" del reembolso por el prestatario al prestamista. Bajo esta amplia palabra cabe muchas figuras: por ejemplo, que el reembolso sea en un único acto, o por parcialidades diferidas entre sí; con o sin reajuste cuando lo que proceda reembolsar sea dinero; sin intereses o con ellos en el mismo caso y ascendente a cuánto, si procede la dación en pago de valores equivalente a los montos dinerarios o a valores por reembolsar, etcétera.

5. En fin, digamos que este reembolso de emolumentos es el objeto de una obligación del prestamista, aunque eventual, porque se gesta si es que hubo emolumentos. Si los hubo, pues, he ahí la tercera obligación que antes dejamos anunciada y que afecta al prestatario.

\section{EJERCICIO DE LOS DERECHOS “POLÍTICOS” EMANADOS DE LOS VALORES RECIBIDOS EN PRÉSTAMO}

Como opuestos a los derecho de contenido patrimonial que causan los valores (y que la Ley N²0.345 denomina “derechos económicos” en el ar- 
tículo $40 \mathrm{~N}^{\circ} 4$ ), tales cuales los intereses, dividendos y otros, se ha extendido el uso de la curiosa expresión "derechos políticos" aparecida en la doctrina y luego extendida a las leyes, para denotar ciertas facultades que no ofrecen contenido patrimonial, pero que corresponden al dueño del valor. Se los ve claramente configurados con respecto a las acciones de sociedades anónimas, cuando se examina el derecho de asistir a las juntas de accionistas, de hacer uso de la palabra en ellas, de elegir directores y de ser elegidos para esos cargos (tal vez de esto es que nació el uso del adjetivo "político"), de impetrar datos y documentos que atañen al comportamiento de la sociedad, etcétera. También los tenedores de bonos tienen algunos derechos de esta clase, como el de asistir a las juntas de tenedores.

Como hemos visto, el artículo $40 \mathrm{~N}^{\circ} 4$, de modo incidental aunque no por ello menos seguramente, atribuye el ejercicio de los derechos patrimoniales causados por un valor prestado al prestatario, aunque deba reembolsar después el emolumento conseguido al prestamista. En materia de "derechos políticos" en cambio, la ley no se pronuncia ella misma sobre la cuestión de cuál de las partes del contrato haya de ejercer los emanados de los valores prestados. En efecto, dice el artículo $40 \mathrm{~N}^{\circ} 5$ de la ley: "Los sistemas establecerán normas para la realización de operaciones de préstamo de valores, las cuales contendrán a lo menos las siguientes materias:/ [...]/ 5. La parte que ejercerá los derechos politicos que puedan emanar de los valores objeto de préstamo". Esto significa que el punto tampoco queda entregado a la libre decisión de las partes del contrato, y debe venir decidido de antemano en las normas que los sistemas tienen que establecer para la ejecución de operaciones de préstamo de valores. Así que las administradoras de sistemas, que es en final de cuentas a quienes corresponde establecer dichas normas, son libres para decidir quién ha de ejercer los "derechos políticos" causados por los valores prestados. Los sistemas pueden entregarlos todos al prestamista o al prestatario; y también algunos a uno de ellos y otros al otro; asimismo, pueden determinar que sean las partes del contrato los que distribuyan como quieran los "derechos políticos" entre ellas. En fin, pueden fijar una distribución y dar libertad a las partes para que ellas la modifiquen, de modo de tener carácter supletorio.

Lo que no parece posible es que las partes del contrato puedan alterar la distribución fijada por las normas sin que se les confiera carácter supletorio.

\section{FUNCIÓN DEL PRÉSTAMO DE VALORES}

Para terminar nuestro estudio, debemos preguntarnos por la función que cumple el préstamo de valores en el interior de un sistema de compensación y liquidación de instrumentos financieros. 
1. Podemos responder que una primera función suya consiste en asegurar el correcto funcionamiento del sistema, como lo dice expresamente, aunque a propósito de un punto específico, el encabezamiento del artículo 38, al iniciar la regulación del préstamo en el título $6^{\circ}$ de la ley. El mercado de valores se cimenta de manera extraordinaria en la confianza que sus intervinientes tienen en cada cual y en el sistema como conjunto, única manera de imprimir celeridad y rapidez a los negocios sobre valores. Así como cuando se trata de la negocialidad concerniente a inmuebles, sus participantes buscan la seguridad de los títulos, en la de valores lo importante es la rapidez en el cambio: fuere impensable aplicar ahí unos procedimientos similares al "estudio de títulos" que se ejecuta cada vez que se va a comprar un inmueble. Pero la única manera de imprimir rapidez a los negocios sobre valores es confiar en que todo lo que dice la contraparte si no es verdadero, resulte serlo, merced a estructuras y procedimientos objetivos destinados a hacer que los acreedores de todos modos vean satisfechos sus créditos asumidos por los demás participantes. Si un corredor de bolsa, por ejemplo, vende tantas acciones de cierta compañía, puede ser que las tenga pero también que no las tenga; en el primer caso se supone que la transferencia acordada se llevará a efecto de manera normal; pero en el segundo caso, cuando el corredor carece de las acciones que vendió, entonces se presenta un problema. Un incumplimiento puede ser peligroso para los sistemas de valores y por ello se trata de que las expectativas siempre sean satisfechas. En este punto cumple una función el préstamo de valores si volvemos a mirar a aquel corredor que asumió ciertos compromisos que no puede cumplir por falta de provisión suficiente, pero que quisiera cumplir. Para ese caso, por ejemplo, queda aconsejado el préstamo de los valores que el corredor de nuestro ejemplo necesita y no tiene y que ahora, una vez recibidos en tal calidad, puede usar para honrar sus compromisos.

2. Pero no queda descartado el empleo del préstamo de valores como operación financiera lucrativa y aun lícitamente especulativa. Un operador podría pedir un préstamo movido por el cálculo de ser mayor que el monto del premio la ganancia conseguida con el precio de su posterior venta, descontado el precio de su ulterior compra para devolverlos. Por ejemplo, si el pronóstico sobre el comportamiento de ciertas acciones altamente valoradas en la actualidad es a la baja, puede ser un buen negocio pedir prestada una cantidad de ellas y luego venderlas en el actual precio alto, para comprarlas, cuando hayan de ser devueltas, en el precio más bajo pronosticado, si, aun después de descontado el premio, la operación deja una ganancia neta consistente en la diferencia del precio de venta y de compra.

3. En fin, el préstamo también puede ser utilizado para mejorar los 
porcentajes de propiedad de los valores involucrados, cuando aquéllos sean relevantes a ciertos efectos. Por ejemplo, si alguien desea mejorar su participación en la junta de accionistas para poder determinar la elección de tantos directores, podría solicitar un préstamo de acciones de las pertinentes, con reserva para sí del ejercicio de los derechos políticos involucrados en ellas (supuesto que las normas del sistema permiten tal reserva).

\section{BIBLIOGRAFÍA}

Código Civil de Chile (19a edición, Santiago, Editorial Jurídica de Chile, 2011).

Código de Comercio de Chile (19a edición, Santiago, Editorial Jurídica de Chile, 2011).

Decreto supremo $\mathrm{N}^{\circ}$ 587, del Ministerio de Hacienda: sobre Sociedades anónimas (DO. de 4 de agosto de 1982).

Historia de la ley 20.345 (Biblioteca del Congreso Nacional).

Ley $\mathrm{N}^{\circ}$ 18.010: Establece normas para las operaciones de crédito y otras obligaciones de dinero (DO. de 27 de junio de 1981).

Ley $\mathrm{N}^{\circ} 18.045$ sobre: Mercado de valores (DO. de 21 de octubre de 1981).

Ley No 18.092, que: Dicta nuevas normas sobre letra de cambio y pagaré (DO. de 14 de enero de 1982).

Ley No 18.552, que: Regula tratamiento de títulos de crédito (DO. de 20 de septiembre de 1986).

Ley $\mathrm{N}^{\circ} 18.876$ que: Establece el marco legal para la constitución y operación de entidades privadas de depósito y custodia de valores (DO. de 5 de diciembre de 1989).

Ley $\mathrm{N}^{\circ} 20.190$ [artículo 14: Ley de prenda sin desplazamiento] (DO. de 5 de junio de 2007).

Ley $\mathrm{N}^{\circ}$ 20.345: sobre Sistemas de compensación y liquidación de instrumentos financieros (DO. de 6 de junio de 2009).

López Santa María, Jorge, Los contratos. Parte general (5a edición, Santiago, Abeledo Perrot - LegalPublishing, 2010). 